Der folgende Text wird über DuEPublico, den Dokumenten- und Publikationsserver der Universität Duisburg-Essen zur Verfügung gestellt.

Diese Version der E-Publikation ist kein Verlagsangebot und kann von einer eventuell ebenfalls veröffentlichten Verlagsversion abweichen.

Schall, Ulrich; Schön, Anja; Zerbin, Dieter; Eggers, Christian; Oades, Robert D.:

Event-related potentials during an auditory discrimination with prepulse inhibition in patients with schizophrenia, obsessive-compulsive disorder and healthy subjects 


\title{
EVENT-RELATED POTENTIALS DURING AN AUDITORY DISCRIMINATION WITH PREPULSE INHIBITION IN PATIENTS WITH SCHIZOPHRENIA, OBSESSIVE-COMPULSIVE DISORDER AND HEALTHY SUBJECTS
}

\author{
ULRICH SCHALL1*, ANJA SCHÖN², DIETER ZERBIN ${ }^{112}$, CHRISTIAN EGGERS ${ }^{2}$ \\ and ROBERT D. OADES ${ }^{2}$
}
RLHK Clinic for General Psychiatry' and Clinic for Child and Adolescent Psychiatry², University of Essen

\begin{abstract}
Prepulse inhibition (PPI) is a measure of the influence of a stimulus (S1) on the response elicited by a second stimulus (S2) occurring shortly afterwards. Most S1/S2 measures of gating have used behavioural startle and the P50 event-related potential (ERP) amplitudes to detect PPI in a simple paired stimulus paradigm. We report on two behavioural (reaction time, RT, and the electromyographically recorded response of the musculus orbicularis oculi, EMG) and 5 ERP measures of PPI where $S 2$ was the target in an auditory two-tone discrimination. Subjects were 21 healthy controls (CON), 11 obsessive-compulsive (OCD) and 9 schizophrenic patients (SCH). The prepulse $100 \mathrm{~ms}$ before $S 2$ induced more omission errors and longer RTs compared to a $500 \mathrm{~ms} S 1-\mathrm{S} 2$ interval in all subjects. PPI was also evident in EMG, P50, N1, P3 but not P2 or N2 amplitudes of CON subjects. SCH patients showed attenuation of PPI on the same measures. OCD patients were characterized only by their slow RT and a marginal attenuation of PPI of the EMG response. A correlational analysis implied separate relationships of ERP indices of PPI to the cognitive and psychomotor consequences of the prepulse on behavioural and discrimination responses. However, $\mathrm{SCH}$ patients showed a general rather than a specific impairment of these indices.
\end{abstract}

Keywords: schizophrenia, obsessive-compulsive disorder, prepulse inhibition, sensory gating, event-related potentials, PSO

\section{INTRODUCTION}

Prepulse inhibition (PPI) is a measure of interference in the processing of a stimulus when it is closely preceded by another (sensory gating). PPI has often been recorded as the reduction of the response to a loud tone when this was preceded by a click. The response may be a startle-blink or a neural response such as an event-related potential (McDowd, Filion, Harris, \& Braff, 1993). By definition perception of the tone is altered by the prepulse: if the tone is a target in a discrimination the selective aspect of perception, namely attention, is affected (Treisman, 1960).

*Correspondence to: Ulrich Schall, MD, PhD, University of Essen, Clinic for General Psychiatry, Virchowstraße 174, 45147 Essen, Germany

We are grateful to Robert Windelschmitt, Jutta Haverkom and Rita Frantska for their technical assistance, to Dr Detlef Bunk for discussion and to Dr Philip Ward (Biological Schizophrenia Research Team, University of New South Wales) for helpful comments on this article. Some initial results were presented in conference proceedings in 1992 (European Journal of Neuroscience. suppl., 5, 226 \& Fortschritte in Neurologie und Psychiatrie, 60 suppl. 1,29 ). U.S. is suppored by a grant of the Deutsche Forschungsgemeinschaft (DFG 626/1-1 and 1-2). 
As the interstimulus intervals (ISI) are usually short (e.g. 100-500 ms) and subjects are sometimes unaware of the soft prepulse, the effect may be largely an automatic attention process. However, occasionally conscious effects on attention at such short intervals have been reported (Hackley, Woldorff \& Hillyard, 1987). This is an important point as PPI as indexed by the startle response has been reported for decerebrate rats (Davis \& Gendelman, 1977) and relevant circuitry includes crucial brainstem contributions (Swerdlow \& Geyer, 1993). In our study of the possible differences in PPI in schizophrenia and OCD, where the weight of evidence is for anomalous function in higher central nervous centres, we are concentrating on the modulatory influences that the forebrain may be exerting on brainstem function.

Both PPI and mismatch negativity (MMN), an ERP measured by the differences of ERP response to two different stimuli and largely an indicator of automatic processes, have been reported to be deficient in schizophrenics (Adler, Pachtman, Franks, Pecevich, Waldo \& Freedman, 1982; Braff, Stone, Callaway, Geyer, Glick \& Bali, 1978; Oades, 1995; Oades, Zerbin \& Eggers, 1993; Shelley, Ward, Catts, Michie, Andrews \& McConaghy, 1991). Some authors did not find an attenuation of PPI on the P50/P1 ERP in schizophrenia (Kathmann \& Engel, 1990) while others have repeatedly replicated the effect, showing a) that it is large at $\mathrm{Cz}$ (Nagamoto, Adler, Waldo, Griffith \& Freedman, 1991) but it decreases in size from $\mathrm{Fz}$ to $\mathrm{Pz}$ (Judd, McAdams, Budnick \& Braff, 1992), b) it is found in half the first degree relatives of schizophrenics (Siegel, Waldo, Mizner, Adler \& Freedman, 1984), c) it may be associated with subsequent N1 attenuation (Waldo, Adler \& Freedman, 1988), and d) it may be independent of indicators of catecholamine metabolism in schizophrenic but not in manic psychosis (Baker, Staunton, Adler, Gerhardt, Drebing, Waldo, Nagamoto \& Freedman, 1990). Further, startle response measures of gating in animals are also catecholamine-dependent (Bubser \& Koch, 1994).

While clinical studies of OCD imply an attentional problem in OCD patients, empirical studies have found specific impairments difficult to replicate (Reed, 1991) and few relate to automatic processes. However, in the context of tomographic studies reporting unusual anatomical and metabolic features in orbitofrontal regions of OCD patients (Swedo, Schapiro, Grady, Cheslow, Leonard, Kumar, Friedland, Rapoport \& Rapoport, 1989) two preclinical studies are relevant. Firstly, from intracranial recordings, gating of ascending sensory systems by extralemniscal tecto-tegmental inputs to the reticular nucleus of the thalamus were described (Velasco \& Velasco, 1979). Further units in the reticular nucleus were driven by stimulation of the orbitofrontal cortex. This resulted in inhibition of firing in the sensory thalamic nucleus. Thus there is a clear substrate for potentially unusual function in the PPI paradigm in OCD patients.

Swerdlow, Benbow, Zisook, Geyer and Braff (1993) reported preliminary findings with OCD patients. They offer a different argument for impaired gating in OCD. They suggest that a loss of "cognitive gating" could explain the intrusion of undesired thoughts. From this we understand them to imply a "leaky filter" in the dialogue between forebrain regions during monitoring and preparatory processes.

The questions we address here are, 1) is the attenuation of P50-PPI in schizophrenia (SCH) replicable under other conditions (e.g., during target discrimination), 2) is PPI simultaneously evident in behavioural and discrimination measures of performance (reaction time (RT), blink reflex and signal-detection measures), 3) are indices of PPI abnormal in $\mathrm{OCD}$ and $\mathrm{SCH}, 4)$ are there prepulse effects on other ERPs occurring later than the P50 
(Perlstein, Fiorito, Simons \& Graham, 1993), e.g. N1, P2, N2 and P3, demonstrating the influence of gating on later processing in the forebrain?

Since completion of our study evidence of some shared neural mechanisms for startle and P50 measures of sensory gating has been reported (Schwartzkopff, Lanberti \& Smith, 1993). But differences were evident in that P50-PPI was less related to startle-PPI than to startle habituation. Our study does not address their proposed relationship between unmodulated P50 amplitude and startle habituation. Our concern was to see whether different measures of gating gave similar results in healthy subjects, were altered in two patient groups, affected measures of discrimination performance and influenced ERPs occurring later than the P50.

The clinically relevant part of these questions concerns diagnostic specificity. We compared performance of a separate diagnostic group, as we have already found that MMN is impaired in young psychotics, both with and without a diagnosis of paranoid schizophrenia (Oades, 1995). OCD was chosen for 3 reasons 1) young psychotics often present with some OCD symptoms prior to decompensation (Eggers, 1968) 2) monoamine dysfunction may occur in psychosis and OCD (dopamine and serotonin, respectively (Rapoport, 1991; Straube \& Oades, 1992), 3) anomalous function in related but different parts of the frontal lobe and neostriatum have been implicated in both illnesses (loc cit.).

\section{METHODS}

\section{Subjects}

Seven male and 4 female subacute psychotic patients were tested; 7 of these were inpatients. Following diagnosis of schizophrenia according to DSM III-R and ICD 10 criteria there remained 6 male and 3 female patients ( 6 paranoid, 2 disorganized and one schizophreniform subtype). Eight received medication ( 5 butyrophenone, 2 phenothiazine, one clozapine: 30 - 1450 chlorpromazine equivalents). They had a mean age of $23.2 \mathrm{y}$ (sd 7, range 15-34y), a performance IQ of 97.2 (sd 15, Raven's standard progressive matrices, SPM) and had received $7-12 y$ of school education.

Eight male and 3 female patients diagnosed with OCD (DSM III-R and ICD 10) were tested; 8 of these were inpatients. Clinical records showed that they had no psychotic features, minimal symptoms of depression and had received no psychotropic medication. They had a mean age of $21.7 \mathrm{y}$ (sd 6.2, range 16-33y), an SPM IQ of 121.2 (sd 13.2) and had received 10-13y of school education.

Ten male and 11 female healthy control subjects who reported no use of psychotropic medication, no major medical problem and no psychiatric illness for themselves or among first-degree relatives took part in the experiment (24.5y sd 2.7, range 17-27y; SPM IQ 125 sd 10). Two controls and one schizophrenic were left-handed. After approval of the protocol by the clinic administration, all subjects consented to participate after being informed on the nature and content of the study. The parents of those under $18 \mathrm{y}$ gave written consent.

\section{Task}

Auditory stimuli were played bilaterally over headphones (Bayer Dynamics DT 48). The prepulse (S1) was an $0.6 \mathrm{~ms}$ alternating rectangular click at $50 \mathrm{dBSL}$ against a background of white noise ( $30 \mathrm{dBSL}$ ). The second pulse (S2) followed at an ISI of 100 or $500 \mathrm{~ms}$ ( $\mathrm{p}=$ 
$50 \%)$ and consisted of a 0.8 or $1.4 \mathrm{KHz}$ tone $(\mathrm{p}=50 \%)$ at $65 \mathrm{dBSL}$ lasting $50 \mathrm{~ms}$ (rise/fall time $10 \mathrm{~ms}$ ). Tone and ISI-condition were presented in a Bernouilli sequence of $100 \mathrm{stim}$ ulus-pairs (= trial) per block with an inter-trial interval (ITI) of 4-6 sec. Each subject received 4-6 stimulus-blocks.

The constraint of the need to obtain at least 80 artifact-free recordings in one session ( 20 per stimulus condition) required a choice of parameters likely to elicit less than maximal response (e.g. ITI (Boutros, Overall \& Zouridakis, 1991); target frequency (Polich, 1990)) and the evaluation of the "relative" PPI ( $100 \mathrm{~ms}$ vs $500 \mathrm{~ms}$ ISI conditions), rather than PPI referring to a no-prepulse condition. In support of our expectation of finding group differences in relative PPI, a differential gating of response (for ERP and startle measures) has been reported for short and long ISIs in healthy and schizophrenic groups (Braff, Grillon \& Geyer, 1992; Nagamoto et al., 1991). However, a no-prepulse baseline was used in pilot work with heaithy subjects (two stimulus blocks requiring and two not requiring response) and is represented in figs. 1 and 2.

\section{Procedure}

The auditory detection threshold of each subject $(0.125-8 \mathrm{KHz})$ was determined immediately before the experiment with an audiometer (Audio-Med BCA3). This allowed individual adjustment of the loudness of the tones for each ear. Subjects relaxed in a reclining soft chair in a small, sound-attenuated, air-conditioned and electrically-isolated room illuminated indirectly by a $25 \mathrm{w}$ lamp and could be observed on closed-circuit video. They were asked to make a 2-tone discrimination with the following instructions in conversational German:

"You will hear high and low tones over the earphones. Please press the button as fast as possible when you hear the high one. You can ignore the low tone. Try to remain as relaxed as possible yet try to concentrate on the tones. Keep your eyes open, try not to blink too much (this disturbs the recording): looking at the small cross on the wall (1.5 maway) may help you concentrate and also reduce disturbing eye-movements. A run of tones lasts but a few minutes. We will need to play several runs but with a pause for relaxation between them-you can tell us how long you wish this to be. Any questions? Now we will have a practice run so that you can get to know the tones."

Measures of perceptual sensitivity (d-prime) and response bias or criterion (beta) were calculated from hit and false alarm rates in $800 \mathrm{~ms}$ post-S2 response windows prior to electrophysiological artifact rejection (Helstrøm, 1960). Sensitivity values of 0.5 for perfect discrimination increase with poorer performance progressing towards chance; criterion values around 1.0 increase as a liberal response bias becomes conservative.

\section{Recording Methods}

EEG recordings were analysed from $\mathrm{Cz}$ tin electrodes (Electrocap International) with mastoid reference (maximal impedance $2 \mathrm{~K} \Omega$ ). The signal was amplified by a Siemens EEG21 (band pass filter $0.2-70 \mathrm{~Hz}$; amplification 12k). EEG epochs were rejected if the EOG exceeded $75 \mu \mathrm{V}, 50-60 \%$ of trials were rejected in the OCD and CON groups and $70-80 \%$ in the SCH group. Artifact-free recordings (80-200: minimum of 20 per stimulus-ISI combination) were digitalized at $250 \mathrm{~Hz}$ until $1300 \mathrm{~ms}$ after $\mathrm{S} 1$ and referred to a $50 \mathrm{~ms}$-baseline pre-S1 using a Compaq 386-20 personal computer. 
We report ERP peak amplitudes measured at $\mathrm{Cz}$ as this site lies furthest from artifact sources in the skull musculature over frontal and temporal regions (Nagamoto et al., 1991). The following windows for peaks following S2 were used (in parenthesis: parallel-test reliability between blocks): P50, 30-80ms ( $r>.94)$; N1 81-140 ms $(r>.94)$; P2, 141-240 $\mathrm{ms}(r>.86)$; N2, 221-320 ms $(r>.71)$; P3, 280-400 ms $(r>.78)$. CNV amplitude was measured at $\mathrm{S} 2$ onset in the $500 \mathrm{~ms}$ condition $(r>.92)$ and subtracted from the ensuing waveform for the assessment of P50.

By definition the acoustic startle response is elicited by a sudden auditory stimulus with a loudness of more than $80 \mathrm{~dB}(\mathrm{SPL})$ (Davis, 1984). Commonly the eye-blink reflex is investigated in most gating studies. Here we report on the electromyographic response of the musculus orbicularis oculi elicited with an intensity of 65 dBSL (S2) which does not induce a visible blinking of the eyes. The mean latencies for the averaged peak response to stimuli were 68-70 ms (sd 2-3) for healthy subjects and 71-73 ms (sd 9-11) for patients in the different conditions (parallel-test reliability between blocks $r>.78$ ). These did not differ significantly in comparison with $60-65 \mathrm{~ms}$ recorded by Braff et al. (1978). The small disparity of the two measures is attributable to the different stimulus parameters used (e.g. loudness). This along with the negligible correlation between P50 and "startle" amplitudes $(r=-.19$ to +.26$)$ and the trivial common variance shared ( $\max .10 \%$ ) confirms the differentiation of P50 and EMG amplitude in our recordings.

\section{Statistical Methods}

A multivariate analysis of variance was used to compare the behavioural and electrophysiological responses (and the differences between ISI-100 and $-500 \mathrm{~ms}$ conditions) separately. Significant effects were followed by univariate analysis and post-hoc Schéffé comparisons (alpha $=5 \%$ ) and are reported in the text. Between condition changes were assessed by 2-tailed paired t-tests: they are referred to in the text but are reported in the figures and legends. Pearson correlations were calculated to show relationships between measures whose overall contribution was assessed by multiple linear regression and the alpha was adjusted by the Bonferroni procedure. Following the initial analysis of discrimination performance ERP measures were collapsed across tones for PPI derivation.

Electrophysiological data were normalized as was deemed necessary to fulfill the requirements for parametric analysis after initially comparing plots of the original data and residuals. Statistical analysis was performed on the calculated values from 0 to +1 . These were adjusted to a scale of -1 to +1 by a linear transformation of the relative differences to retain a visual semblance to the recorded data in the figures.

\section{RESULTS}

\section{Discrimination, Reaction Time (RT) and "Startle" Response (EMG)}

SCH and OCD patients made more errors of omission $(F(2,38)=7.3, p=0.002$; Schéffé $p$ $<0.05)$ but not more errors of commission $(F(2,38)=1.5, p<0.3)$ than CON. For all subjects a prepulse $100 \mathrm{~ms}$ before $S 2$ facilitated errors of omission with respect to the $500 \mathrm{~ms}$ condition (significant for $\mathrm{CON}$ and $\mathrm{SCH}$, fig. 1, upper left) without differentiating between 
groups $(F(2,38)=3.2, p<0.05$, Schéffé not significant $)$. There were no within or between group differences in errors of commission (Fig. 1, lower left).

Yet the signal detection indices of sensitivity (d-prime) did differ between groups $(F(2,38)$ $=3.6, p=0.04$ ). SCH showed poorer sensitivity than CON (Schéffé $p<0.05$ ). Further, SCH sensitivity was worse in the $100 \mathrm{~ms}$ than the $500 \mathrm{~ms}$ condition (Fig. 1, lower right). This difference was larger than for $\operatorname{CON}(F(2,38)=3.5, p=0.04$, Schéffé $p<0.05)$.

CON response bias was more liberal than for either the OCD or $S C H$ patients $(F(2,38)=$ $7.4, p=0.002$, Schéffé $p<0.05$ ). Bias was more conservative in the $100 \mathrm{~ms}$ than the $500 \mathrm{~ms}$ condition only for the SCH group (Fig. 1, upper right) but the difference between conditions was not larger for SCH than CON groups $(F(2,38)=2.2, p=0.12)$. Thus the presence of a prepulse altered the discrimination strategy of both patient groups, whereby the increased conservatism probably reflected the perceived difficulty. But perceptual sensitivity was significantly poorer only in the SCH group and here particularly in the $100 \mathrm{~ms}$ condition.

In both conditions the SCH and OCD groups responded approximately $20 \%$ slower than the CON group $(F(2,38)=8.7, p=0.001$, Schéffé $p<0.05)$. RTs were marginally but significantly faster in the $500 \mathrm{~ms}$ than in the $100 \mathrm{~ms}$ condition for CON and SCH groups (Fig. $2 \mathrm{~A})$ but this difference did not separate the groups $(F(2,38)=1.3, p=0.3)$. This suggests a small PPI effect in all groups.

"Startle" responses to $\$ 2$, while broadly similar between groups, showed a marked increase in the $500 \mathrm{~ms}$ with respect to the $100 \mathrm{~ms}$ condition alone for CON (Fig. 2B). This increased response in the $500 \mathrm{~ms}$ condition was not seen in SCH or OCD groups $(F(2,38)$ $=4.9, p=0.01$ ) and confirmed absent in the SCH group (Schéffé $p<0.05$ ). Thus this measure reflected PPI in the CON group but not in the patients.

\section{Event-related Potentials (ERPs)}

The CNV was evaluated in the $500 \mathrm{~ms}$ condition at $\mathrm{S} 2$ onset at $\mathrm{Cz}$. The mean amplitude for CON of $2.0 \mu \mathrm{V}$ (sd 1.2) was higher than for the SCH (1.4 $\mu \mathrm{V}$, sd 0.9) or the OCD groups (1.1 $\mu \mathrm{V}$, sd 1.6). As a result of marked variability differences (OCD 43\%, SCH 27\%) were not significant $(F(2,38)=2.6, p=0.08$ : fig. $2 \mathrm{C})$.

Mean P50 amplitudes varied between groups and conditions between 0.1 and $1.4 \mu \mathrm{V}$. There were no between group differences in the amplitude of response to target and nontarget $(F(2,38)=3.0, p=0.06)$ independent of condition. The CON group alone showed a significantly smaller P50 response in the $100 \mathrm{~ms}$ vs the $500 \mathrm{~ms}$ condition (fig. 3). The difference appeared to be larger than for the other groups $(F(2,38)=3.3, p<0.05)$ but this was not confirmed by the Schéffé posthoc test. Thus we could demonstrate PPI of P50 amplitude in healthy subjects at 100 vs $500 \mathrm{~ms}$ but not in patients.

Mean N1 amplitudes varied from 2.7 to $9.7 \mu \mathrm{V}$ between conditions and groups $(F(2,38)=$ $6.5 ; p=.004$; Schéffé $\mathrm{SCH}<\mathrm{CON}$ and $\mathrm{OCD} ; p<.05$ ), whereby each group showed clearly smaller amplitudes in the 100 than in the 500 ms condition $(F(1,38)=85.7 ; p<.0001 ;$ fig. 3$)$. Target and non-target $\mathrm{N} 1$ ampiltudes differed significantly across groups $(F(1 ; 38)=13.7 ; p=$ .001 ) but there were no group differences or significant interactions (e.g. PPI by target/nontarget: $F(1,38)=3.8 ; p=.06)$. Hence a PPI effect on $\mathrm{N} 1$ amplitude was evident in all subjects.

There were no group differences of $\mathrm{P} 2$ or $\mathrm{N} 2$ amplitude elicited by target and non-target stimuli $(F(2,38)=0.04 / 0.7, p=0.96 / 0.51$, respectively). No PPI effects $(100 \mathrm{vs} 500 \mathrm{~ms}$ condition) were evident either within or between groups on the amplitudes of the $\mathrm{P} 2(F(2,38)$ $=0.6, p=0.54)$ or the $\mathrm{N} 2$ component $(F(2,38)=0.09, p=0.91$; fig. 3$)$. 


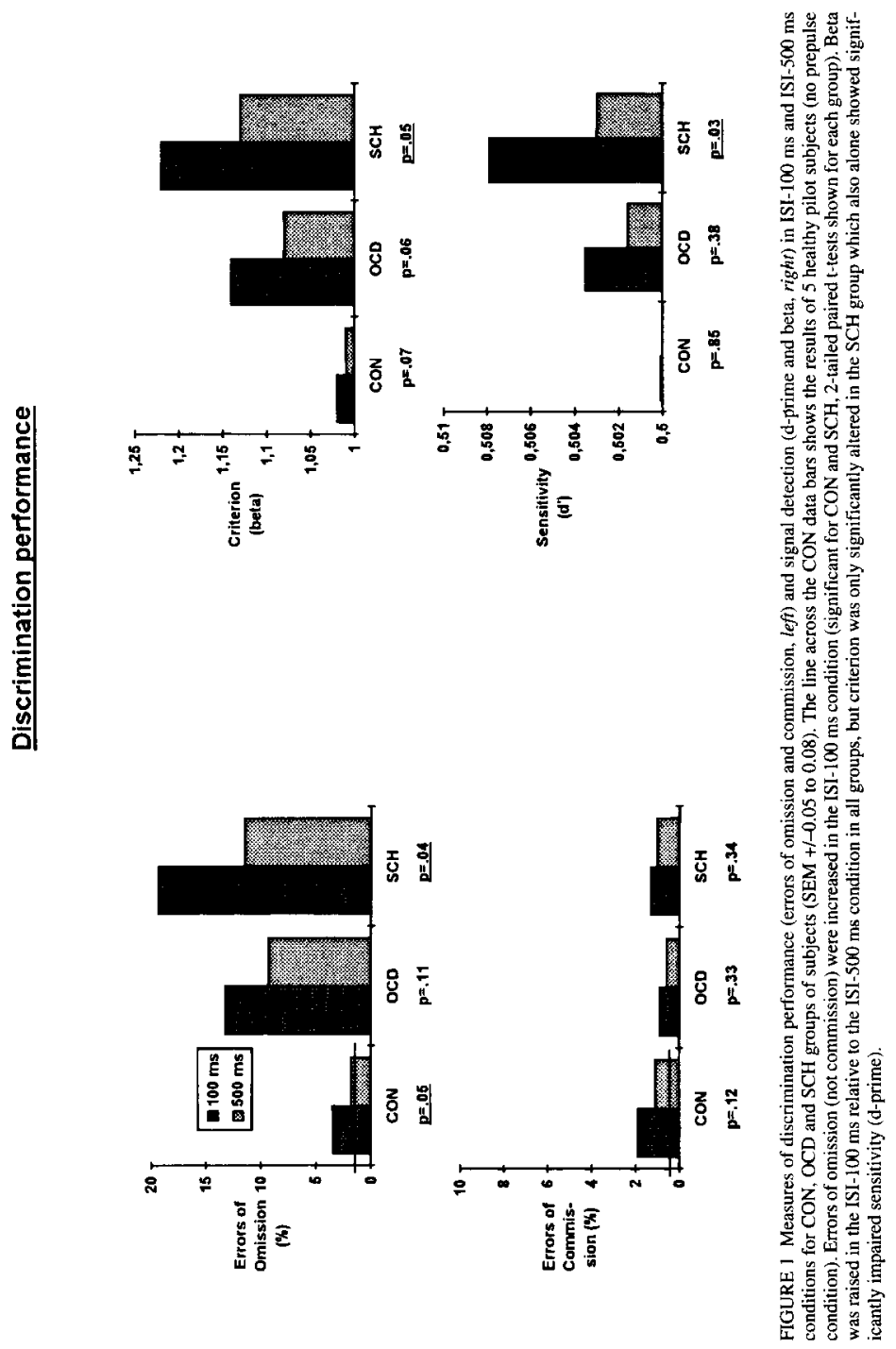


A

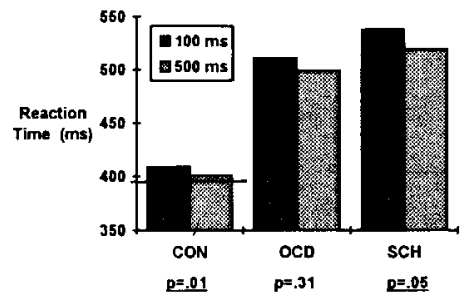

B

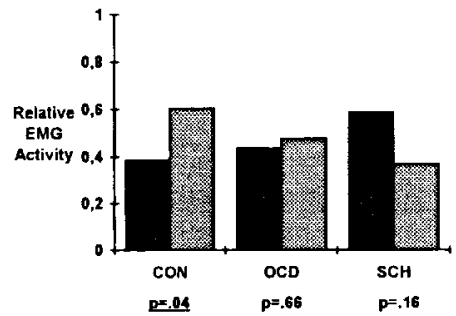

C

CON OCD SCH

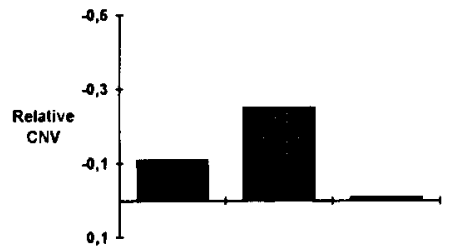

FIGURE 2 A. Measures of reaction time (RT, ms) in ISI- $100 \mathrm{~ms}$ (dark bars) and ISI-500 ms conditions (light bars) for CON, OCD and SCH groups where the horizontal line represents pilot subject performance (legend, Fig. 1). Between-condition 2-tailed paired t-tests are reported for each group. B. Normalized measures of averaged EMG activity (Min-Max, 0 to +1 ) in response to $\mathrm{S} 2$ in ISI-100 $\mathrm{ms}$ and $500 \mathrm{~ms}$ conditions. C. Normalized CNV values (Min-Max, -1 to +1 ) were calculated from data gathered in the ISI-500 ms condition at $\mathrm{Cz}, 500 \mathrm{~ms}$ after $\mathrm{S} 1$ for CON, OCD and SCH groups. 


\section{ERPs: 100 vs. $500 \mathrm{~ms}$ prepulse intervall}

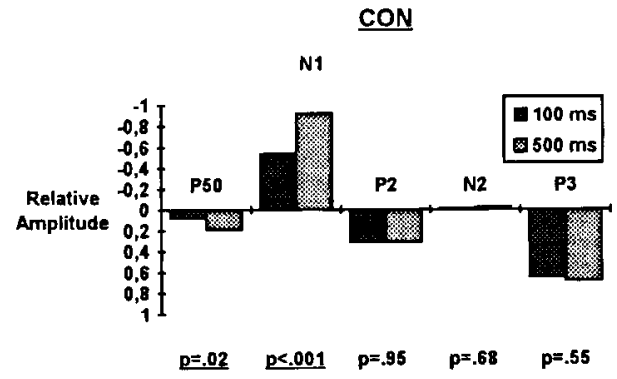

\section{OCD}

N1

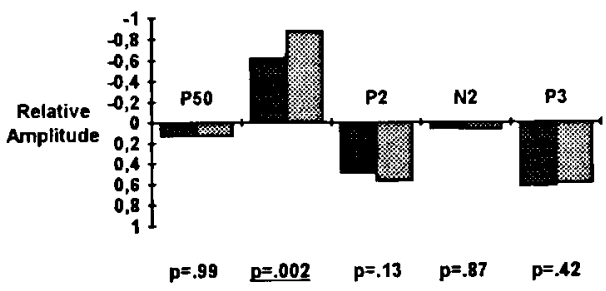

$\underline{\text { SCH }}$

N1

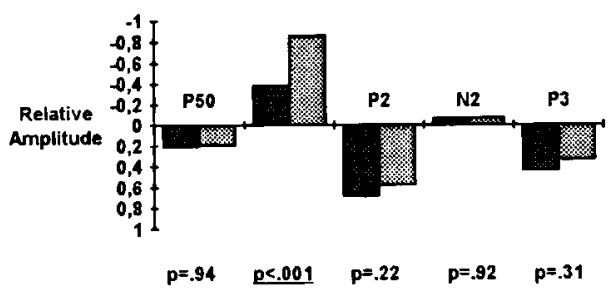

FIGURE 3 Nonnalized (Min-Max) amplitudes for the P50, N1, P2, N2 and P3 components (collapsed across stimulus type) are shown for CON, OCD and SCH groups in the ISI-100 ms (dark shaded bars) and ISI-500 ms conditons (light shaded bars). The normalization is described in the statistical methods section. 
P3 amplitudes ranged from 3.1 to $5.9 \mu \mathrm{V}$ between conditions and groups. Apparent group differences of $\mathrm{P} 3$ amplitude elicited by target vs non-target stimuli $(F(2,38)=3.3, p<0.05)$ were not confirmed posthoc. There were no group differences in the effect the prepulse had on $\mathrm{P} 3$ amplitude in the 100 vs $500 \mathrm{~ms}$ condition $(F(2,38)=1.1, p=0.34$, fig. 3$)$ but a significant PPI by target/non-target interaction across groups $(F(1,38)=5.9 ; p=0.2)$.

\section{Within Group Target/Non-Target Differences}

Grand mean waveforms obtained after each of two stimulus types in both ISI-conditions are shown in fig. 4. This far we have examined the role of stimulus-target features (across ISI-condition) and ISI-condition (across stimulus-type) in group differences. We now ask if there was a between stimulus effect within an ISI condition for the 2 components showing PPI effects (P50 and $\mathrm{N1}$ ) and the P3.

P50 amplitudes elicited by target and non-target stimuli did not differ in the $100 \mathrm{~ms}$ nor in the $500 \mathrm{~ms}$ condition for CON or OCD groups, but were marginally larger (102-104\%) after the target in both cases. However, in the $\mathrm{SCH}$ group the target elicited P50 was larger $(115-118 \%)$ in both ISI conditions ( $p<0.05$ for ISI- $100 \mathrm{~ms}$ ).

In Figure 5 it may be seen that non-target $\mathrm{N} 1$ amplitudes were significantly larger, only in the $500 \mathrm{~ms}$ condition in $\mathrm{CON}$ and $\mathrm{SCH}$ groups. OCD data showed a similar non-signif-

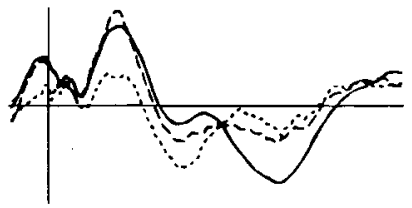

s2

Non-Target/100ms

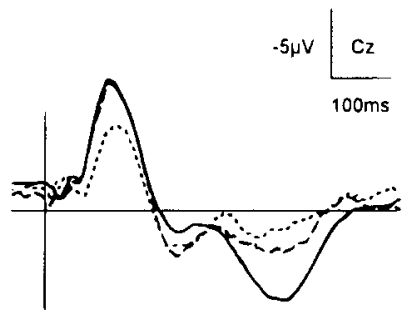

S2
Non-Target $/ 500 \mathrm{~ms}$

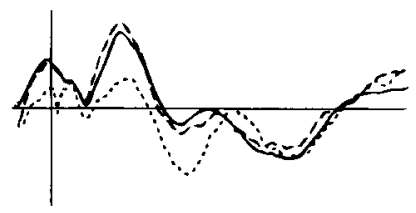

s2

FIGURE 4 Grand mean waveforms (negative up, baseline: $50 \mathrm{~ms}$ pre-S1) elicited in a discrimination by $0.8 \mathrm{KHz}$ (standard) and $1.4 \mathrm{KHz}$ tones (target) at $\mathrm{Cz}$ when a click preceded each tone by either $100 \mathrm{~ms}$ (top) or $500 \mathrm{~ms}$ (bottom) for 21 healthy control (CON, solid line), 9 schizophrenic ( $\mathrm{SCH}$, dotted line) and 11 obsessive-compulsive subjects (OCD, dashed line). 


\section{ERPs: target vs. non-target}

$100 \mathrm{~ms}$

$500 \mathrm{~ms}$
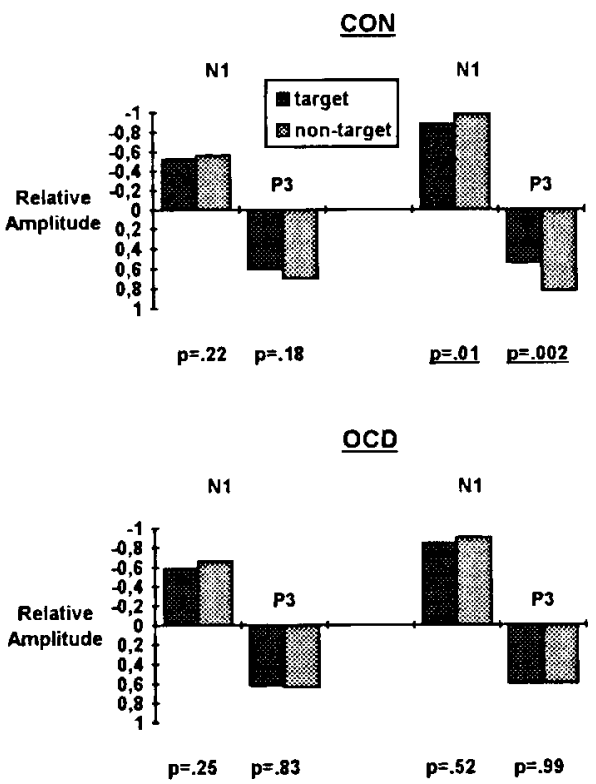

$\underline{\mathrm{SCH}}$

N1

N1

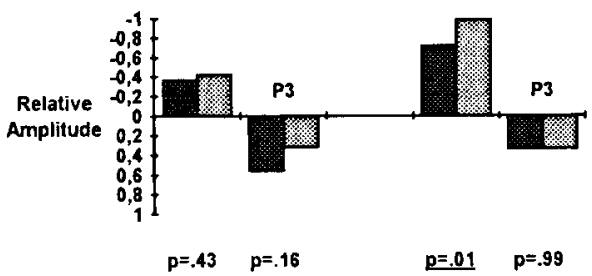

FIGURE 5 Normalized (Min-Max) amplitudes for the N1 and P3 components after target (dark shaded bars) and non-target stimuli (light shaded bars) are shown for CON. OCD and SCH groups in the ISI- $100 \mathrm{~ms}$ (left) and ISI$500 \mathrm{~ms}$ conditons (right). The normalization is described in the statistical methods section. 
icant relationship. By contrast non-target $\mathrm{P} 3$ amplitude was the larger only in the $\mathrm{CON}$ group. The implication is that S1 may interfere with early processing (e.g., N1) of targetspecific features in patients and healthy subjects, but that later consequences of $\mathrm{S} 1$ on processing target-features (reflected by P3) are more evident in healthy subjects. The next section examines further the relationship of these ERPs to discrimination measures.

\section{Relationships Between Measures}

Are the different $\mathrm{S} 2$ responses that are sensitive to $\mathrm{S} 1$ related to the discrimination measures? Multiple linear regressions for PPI of RT, "startle" and the 5 ERPs explained 36-50\% of the variance in errors of omission, perceptual sensitivity and criterion (Table 1). There was no significant relationship to errors of commission.

The extent of RT-PPI, shown more or less by all groups, correlated with d-prime and beta-criterion. The relative slowing of response in the $100 \mathrm{~ms}$ condition through the prepulse was associated with poorer perceptual sensitivity and an increasingly conservative response strategy. But PPI of "startle" or P1 responses to S2 in the 100 vs $500 \mathrm{~ms}$ condition, not seen in patients, did not correlate significantly with discrimination measures. PPI of the $\mathrm{N} 1$ response ( $100 \mathrm{vs} 500 \mathrm{~ms}$ condition) was also unrelated to discrimination. But, while the impaired $\mathrm{N} 1$ after target stimuli in the $500 \mathrm{~ms}$ condition was unrelated to discrimination measures, the impaired $\mathrm{P} 3$ response related to errors of omission, d-prime and beta-criterion (Table $1, \mathrm{N1}_{\mathrm{d}}$ and $\mathrm{P} 3_{\mathrm{d}}$ ).

\section{DISCUSSION}

This is the first report we are aware of on PPI in a 2-tone discrimination paradigm for healthy and psychiatric subjects. Recently Dawson, Hazlett, Filion, Nuechterlein, and Schell (1993) asked subjects to discriminate soft $\$ 1$ prepulses as a function of pitch and found that the attention condition enhanced PPI of the startle response in healthy but not psychotic subjects. It was unexpected that the ignored S1 elicited no PPI differences between groups who, in addition, all showed PPI in terms of electrodermal responses. However, our study is not comparable. They chose to investigate the effect of controlled attention to S1 on S2 processing, whereas we studied the effect of $\mathrm{S} 1$ on attention to $\mathrm{S} 2$.

Our basic stimulus presentation method was similar to Braff et al. (1992) who used a quieter prepulse than test stimulus, but differed from Nagamoto et al. (1991) who used similarly loud stimuli. Both research groups reported PPI attenuation in schizophrenics. Use of a quieter prepulse, as in our study, is claimed to produce more robust reponses. But working against this, we used a shorter sub-optimal ITI (Boutros et al,, 1991). This along with our use of the $500 \mathrm{~ms}$ ISI condition rather than a single stimulus condition for comparison reflected the need to obtain a sufficient artifact-free recordings in 4 stimulus conditions in one session from psychiatric patients.

With regard to ERP evaluation, there are several methods for measurement of response (e.g., peak maxima within a given window or area under a negative or positive wave in a given latency band) but there is no unequivocal evidence in favour of the one or the other. With respect to P50 we chose to measure the voltage of the positive deflection within a 30-80ms window following for example, Waldo, Gerhardt, Baker, Drebing, Adler, and 


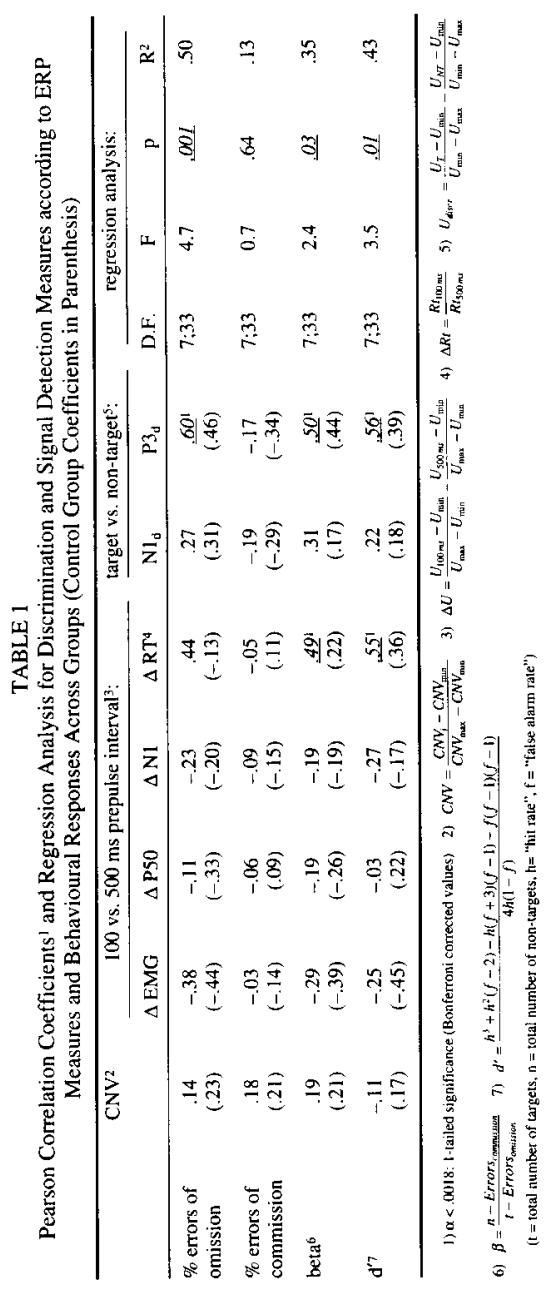


Freedman (1992). Even where integration methods were preferred (Boutros et al., 1991) the method we used was resorted to in difficult cases. Most studies do not report on the influence of the CNV. Our subtraction of this negative drift evident in the $500 \mathrm{~ms}$ condition represents an improvement in absolute measurement of P50.

Data were analysed from $\mathrm{Cz}$ to be consistent with the majority of published reports and to be able to study data where they are likely to be most free of muscular artifact (Nagamoto et al., 1991). But it must be acknowledged that no site will be totally free of such interference. At first we were concerned about the small target- vs non-target-elicited P3 amplitude at $\mathrm{Cz}$. Here it should be noted that $\mathrm{P} 3$ amplitude decreases with increased target probability (we used 50\%). Increased positivity of $\mathrm{P} 3$ at $\mathrm{Cz}$ to non-targets in a discrimination, thus indicating a decreased cortical excibility, may also reflect the inhibition of the more likely automatic tendency to respond (or "Go" vs "NoGo") in this controlled process (Schupp, Lutzenberger, Rau \& Birbaumer, 1994). Finally caution should be exerted in the interpretation of the absence of changes of beta. The number of errors of commission contributing to this measure were small for all groups in each condition.

Our main findings will be discussed in relation to the questions addressed in the introduction, separately for SCH and OCD groups.

\section{SCH vs CON Groups}

Collapsing across stimulus-type in a discrimination, sensory gating as measured by PPI of the P50-ERP and the averaged response of the musculus orbicularis oculi elicited by $\mathrm{S} 2$ was evident in the ISI- $100 \mathrm{~ms}$ vs ISI-500 $\mathrm{ms}$ condition in CON and not in the SCH group. This is a replication under different conditions of results obtained by other groups (McDowd et al., 1993). But more sensory gating in the $100 \mathrm{~ms}$ condition according to the behavioural measures of RT and errors of omission was a feature of both $\mathrm{CON}$ and $\mathrm{SCH}$ groups. Gating was also evident in the N1 measure for both $\mathrm{CON}$ and SCH subjects, replicating the results of Nagamoto, Adler, Waldo, Griffith, and Freedman (1991) and Roth, Horvarth, Pfefferbaum, and Kopell (1980), but not evident in P2, N2 or P3 measures.

With regard to the discrimination, $\mathrm{SCH}$ subjects alone showed impaired signal detection measures (perceptual sensitivity and beta-criterion) and more so in the 100 vs the $500 \mathrm{~ms}$ condition. However, on ERP measures the prepulse interfered with $\mathrm{N} 1$ and $\mathrm{P} 3$ response to the target (compared to non-target) in the CON group but only the $\mathrm{N} 1$ response in the $\mathrm{SCH}$ group. That is to say prepulse inhibition of target $\mathrm{P} 3$ processing was not evident in $\mathrm{SCH}$ subjects. These effects were more pronounced in the 500 than the $100 \mathrm{~ms}$ condition.

\section{OCD Responses}

Sensory gating as measured by decreased P50 and EMG responses in the 100 vs $500 \mathrm{~ms}$ condition was not evident in the OCD group (fig. 2 and 4, paired t-tests). But a between group difference could not be confirmed posthoc. This is a tentative confirmation the report by Swerdlow et al. (1993) but is qualified by the problem of a type 2 error. Like the other subjects, OCD tended to show a larger PPI effect in the 100 than the $500 \mathrm{~ms}$ condition on the behavioural measures of RT and errors of omission. Similarly they showed more gating of the Nl response in the 100 ms condition, but like the other groups there were no effects on P2, N2 or P3.

Signal-detection measures for OCD subjects were intermediate between CON and SCH data with the response criterion being significantly more conservative than in $\operatorname{CON}(500<$ 
$100 \mathrm{~ms}$ condition). N1 and P3 responses to target and non-target in 100 and $500 \mathrm{~ms}$ conditions were surprisingly similar. However, the apparent absence of a sensory gating effect was not confirmed on a group comparison.

\section{Gating and Discrimination: An Interpretation of CON and SCH Results}

On a number of measures where a soft click shortly precedes a conditioned stimulus (by $100 \mathrm{~ms}$ or $500 \mathrm{~ms}$ ) there are both psychomotor and cognitive consequences for the discrimination in healthy and mentally ill subjects. These effects vary with the S1-S2 interval, they do not universally affect all response measures and are evident even if the subjects are not aware of the prepulse (personal observation).

Two distinctive functions of selective attention are relevant to our results (Posner \& Dehaene, 1994). First the brain enhances processing of a selected stimulus with respect to others. Second processing of this stimulus is directed towards the appropriate cortical areas (channel allocation). These processes are at least in part reflected by the P50 and N1 components, respectively. In tests of visual covert orienting of attention P50 was impaired after a false cue with respect to conditions of no cue or correct cue (Luck and Hillyard, 1994). In contrast N1 was enhanced specifically after correct cues.

In our PPI paradigm P50 and EMG responses in the $100 \mathrm{~ms}$ condition showed the effect of interference of the prepulse in the CON but not the SCH group. For healthy subjects the consequence was that their choice strategy was relatively liberal (beta-criterion). For SCH subjects the perception of the prepulse made the discrimination more difficult as was indicated by a relatively conservative strategy. For these $\mathrm{SCH}$ subjects the increased difficulty impaired measures of perceptual sensitivity and thus more errors of omission were incurred. Thus we suggest for different reasons the effect of a prepulse $100 \mathrm{~ms}$ before $\mathrm{S} 2$ increased RT in both groups; for CON because they had difficulty in selectively attending to the relevant stimulus, for $\mathrm{SCH}$ because they were attending to three stimuli ( $\mathrm{S} 1, \mathrm{~S} 2$ at 0.8 and $1.4 \mathrm{KHz}$ ), a more difficult discrimination. Therefore it is not surprising to find that the second attentional process of allocating a channel for further processing, indexed by $\mathrm{N} 1$, was also reduced across the eliciting stimuli in both subject groups.

It is not easy to explain why the effect of the prepulse at $100 \mathrm{~ms}$ ISI indexed by ERP components stopped at this moment in the temporal sequence of information processing. $\mathrm{P} 2, \mathrm{~N} 2$ and $\mathrm{P} 3$ components seemed unaffected by the prepulse in the ISI-100 ms condition in all subjects. This is evidence for resilient homeostatic mechanisms of information processing where either processing demands increase (e.g., PPI in CON) or mechanisms may be impaired (e.g. SCH group).

However, effects dependent on the nature of $\mathrm{S} 2$ were observed in the ISI-500 $\mathrm{ms}$ condition. Here it is important to emphasize features of our experimental design that differ from other PPI work. Firstly, S2 could be either a target or non-target in a discrimination and secondly, we looked for ERP component changes much later after $S 2$ than other reports which have shown that PPI is most evident with an ISI of $60-120 \mathrm{~ms}$ (Nagamoto et al., 1991). Where attention has been drawn to $S 1$ either through salience (Nagamoto et al., 1989) or because there were two types of $S 1$ to be discriminated (Dawson et al., 1993) prepulse effects have been noted at much longer ISIs ( $500 \mathrm{~ms}$ or more). These intervals recall those at which backward masking is most effective (120-500 ms; Braff \& Saccuzro, 1985). 
In this context it is of interest but not surprising that all subjects showed a reduced N1 after the target vs the non-target stimulus ( $500 \mathrm{~ms}$ condition), given that $\mathrm{N} 1 \mathrm{may}$ index the allocation of the channel for further stimulus analysis to the appropriate part(s) of the cortex (see, first paragraph of this section). Of more interest is that the "interference" effect lasted to include the P3 component in CON but not SCH subjects. Thus we can speak of the attenuation of PPI on the target-P3 in $\mathrm{SCH}$ in the $500 \mathrm{~ms}$ condition. This reflects impaired homeostatic mechanisms in information processing in SCH subjects that, in retrospect, might have been predicted given that they show impaired P3 responses in three-tone discriminations (Pfefferbaum, Wenegrat, Ford, Roth \& Kopell, 1984; Oades, submitted).

\section{Biological Bases of Gating and of Illness}

The importance of these results are that they show there are consequences of the prepulse presentation for learning (e.g. on response decision and errors) and not automatic behavioural responses alone. SCH patients are impaired across a range of PPI measures, OCD patients are remarkable only in their slowness of response and mildly attenuated P50-PPI response.

\section{Subject Groups}

Could the illness account for the extent of the impairment in $\mathrm{SCH}$ patients? A consideration of neurotransmitter systems may support this idea. Animal (and human) studies of PPI have implicated opioid, dopaminergic (Swerdlow, Caine \& Geyer, 1991), noradrenergic (Waldo et al., 1992), cholinergic (Wu, Jenden, Fairchild \& Siegel, 1993), GABAergic (Swerdlow, Braff \& Geyer, 1990), and glutamergic systems (Hoffman, Donovan \& Cassella, 1993) in the mediation of PPI. There is an uneven distribution of evidence that many of these systems function anomalously in many schizophrenics (Straube \& Oades, 1992). Further it is unlikely that neuroleptic medication is responsible as there are reports of haloperidol and clozapine tending to improve PPI and normalize P50 responses (Boutros, Zouridakis, Rustin, Peabody \& Warner, 1993; Hoffman et al., 1993; caveat, the results are qualified in terms of dose and subgroup). Our patients were free of cholinergic medication.

Arguments in terms of regional brain function follow the same direction. It appears that parts of the brainstem and pons are crucial to PPI and can be modulated by frontal and hippocampal activity. However, the evidence is not undisputed (Butler, Jenkins, Geyer \& Bragg, 1990; Swerdlow \& Geyer, 1993 versus Hammond, 1973 \& 1974). Many other studies imply problems in frontal-temporal dialogue in many schizophrenics (Straube \& Oades, 1992).

But we should point out that while it would be parsimonious to suppose a common defect underlying the attenuation of PPI according to several measures, our finding of differential effects between groups of PPI on target-P3 (related to discrimination) and PPI on P50 and "startle" responses (not related to discrimination) suggests that automatic and controlled mechanisms may be discretely affected.

The OCD group here provides a contrast. From medication responsiveness (Pigott, Pato, Bernstein, Grover, Hill, Tolliver \& Murphy, 1990), blood (Hanna, Yuwiler \& Cantwell, 1991) and urine measures (Oades, Röpcke \& Eggers, 1994) there is reason to believe that OCD subjects have unusually high serotonin, adrenalin and HVA/MHPG levels. Curiously as yet activity of the former two transmitters has not been implicated in PPI. But it may be that altered catecholamine activity underlies the PPI attenuation we and Swerdlow et al. (1993) observed in startle measures. 
The proximal basis of the effect may lie with orbitofrontal influence on thalamic function (see introduction), the ultimate impairment may lie in the orbitofrontal-amygdala axis (and perhaps basal ganglia, within which, historically, the amygdala has been included). Pribram and McGuinness (1993) argue that orbitofrontal arousal processes interact with the behavioural activation systems of the basal ganglia and that serotonin and nordrenergic systems are relevant to the amygdaloid role. Supporting this conceptualization are the increased monoamine measures in OCD just mentioned and the increased PET measures of glucose metabolism in frontal, orbital and cingulate regions (Swedo et al., 1989) along with MRI differences seen in caudate regions (Scarone, Colombo, Livian, Abbruzzese, Ronchi, Locatelli, Scotti \& Smeraldi, 1992).

\section{Component Measures}

The attenuation of PPI can be conceptualized as the reduced ability to allow immediate (temporal) context to influence perception (cf. our results on the effect of PPI on discrimination performance). Thus it is not surprising that acute schizophrenics have difficulty in suppressing unhelpful aspects of stimulus context in learning (latent inhibition; Baruch, Hemsley \& Gray, 1988) or learn more rapidly about superfluous cues in learning (conditioned blocking; Oades, Bunk \& Eggers, 1992) or have difficulty to see the wood for the trees in tests of Gestalt perception (Schwartz-Place \& Gilmore, 1980). Why N1, P2 and N2 ERPs were different in this connection remains for further study.

In conclusion, if we conceptualize the PPI-attenuation in schizophrenia in terms of permiting more stimuli to affect information processing and we accept our results showing effects on a number of mechanisms then we have a powerful paradigm 1) for exploring the neural and pharmacological influences on the substrates of a number of cognitive mechanisms and 2) for monitoring the efficacy of various forms of therapy, be they psycho- or pharmacotherapeutic, on psychotic cognitive performance, where the development of appropriate gating processes may play an important etiological role (Eggers, 1991).

\section{REFERENCES}

Adler, L. E., Pachtman, E., Franks, R. D., Pecevich, M., Waldo, M. C. \& Freedman, R. (1982). Neurophysiological evidence for a defect in neuronal mechanisms involved in sensory gating in schizophrenia. Biological Psychiatry, 17, 639-654.

Baker, N. J., Staunton, M. Adler, L. E., Gerhardt, G. A., Drebing, C., Waldo, M., Nagamoto, H. \& Freedman, R. (1990). Sensory gating deficits in psychiatric inpatients: relation to catecholamine metabolites in different diagnostic groups. Biological Psychiatry, 27, 519-528.

Baruch, I., Hemsley, D. R. \& Gray, J. A. (1988). Differential peformance of acute and chronic schizophrenics in a latent inhibition task. Journal of Nerwous and Mental Disease, 176, 598-606.

Boutros, N. N., Overall, J. \& Zouridakis, G. (1991). Test-retest reliability of the P50 mid-latency auditory evoked response. Psychiatry Research, 39, 181-192.

Boutros, N. N., Zouridakis, G., Rustin, T., Peabody, C. \& Wamer, D. (1993). The P50 component of the auditory evoked potential and subtypes of schizophrenia. Psychiary Research, 47, 243-254.

Braff, D. L. \& Saccuzzo, D. P. (1985). The time course of information processing deficits in schizophrenia. American Journal of Psychiatry, 142, 170-174.

Braff, D. L., Stone, C., Callaway, E., Geyer, M., Glick, I. \& Bali, L. (1978). Prestimulus effects on human startle reflex in normals and schizophrenics. Psychophysiology, 15, 339-343.

Braff, D. L., Grillon, C. \& Geyer, M. A. (1992). Gating and habituation of the startle reflex in schizophrenic patients. Archives of General Psychiatry, 49, 206-215. 
Bubser, M. \& Koch, M. (1994). Prepulse inhibition of the acoustic startle response of rats is reduced by 6-hydroxydopamine lesions of the medial prefrontal cortex. Psychopharmacology, //3, 487-492.

Butler, R. W., Jenkins, M. A., Geyer, M. A. \& Braff, D. L. (1990). Wisconsin card-sorting deficits and diminished sensorimotor gating in a discrete subgroup of schizophrenic patients. In Tamminga, C. A.\& Schulz, S. C. (Eds.). Schizophrenia. New York: Raven Press.

Davis. M. (1984). The mammalian startle response. In Eaten. R. C. (Ed.) Neural mechanisms of startle behavior. New York: Plenum Publishing Corporation.

Davis. M. \& Gendelman, P. M. (1977). Plasticity of the acoustic startle response in the acutely decerebrate rat. Journal of Comparative and Physiological Psychology, 91, 549-563.

Dawson, M. E., Hazlett, E. A., Filion, D. L., Nuechterlein, K. H. \& Schell, A. M. (1993). Attention and schizophrenia: impaired modulation of the startle reflex. Journal of Abnormal Psychology, 102, 633-641.

Eggers, C. (1968). Zwangszustände und Schizophrenie. Fortschritte der Neurologie-Psychiatrie. 36, 576-589.

Eggers, C. (1991). Stimulus-barrier model of schizophrenia: convergence of neurobiological and developmental-psychological factors. In Eggers C. (Ed.), Schizophrenia and Youth (pp. 29-42). Heidelberg: SpringerVertag.

Hackley, S. A., Woldorff. M. \& Hillyard, S. A. (1987). Combined use of microreflexes and event-reiated brain potentials as measures of auditory selective attention. Psychophysiology, 24, 632-647.

Hammond, G. R, (1973). Lesions of the pontine and medullary reticular formation and prestimulus inhibition of the acoustic startle reaction in rats. Physiology and Behavior, 10, 239-243.

Hammond, G. R. (1974). Frontal cortical lesions and prestimulus inhibition of the rat's acoustic startle reaction. Physiological Psychology, 2, 151-156.

Hanna, G. L.. Yuwiler, A. \& Cantwell, D. P. (1991). Whole blood serotonin in juvenile obsessive-compulsive disorder. Biological Psychiatr, 29, 738-744.

Helstrøm, C. W. (1960). Statistical theory of signal detection. New York: Academic Press.

Hoffman, D. C., Donovan, H. \& Cassella, J. V. (1993). The effects of haloperidol and clozapine on the disruption of sensorimotor gating induced by the non-competitive glutamate antagonist MK-80 I. Psychopharmacology, $/ 1 /, 339-344$

Judd, L. L., McAdams, L., Budnick, B. \& Braff, D. L. (1992), Sensory gating deficits in schizophrenia: new results. American Joumal of Prwhiatn: 149, 488-493.

Kathmann. N. \& Engel, R. R. (1990). Sensory gating in normals and schizophrenics: Faihure fo find strong P50 supression in normals. Biological Psychiatry, 27, 1216-1226.

Luck, S. J. \& Hillyard, S. A. (1994). Spatial filtering during visual search: evidence from human electrophysiology. Journal of Experimental Psychology: Hunan Perception and Performance in press.

McDowd, J. M., Filion, D. L., Harris, M. J. \& Braff, D. L. (1993). Sensory gating and inhibitory function in latelife schizophrenia. Schizophrenia Bulletin, 19.733-746.

Nagamoto, H. T., Adler, L. E., Waldo, M. C. \& Freedman, R. (1989). Sensory gating and normal controls: effects of changing stimulation interval. Biological Psychiatry, 25, 549-56i.

Nagamoto, H. T. Adier. L. E., Waldo. M. C. Griffith. J. \& Freedman, R. (199I). Gating of auditory response in schizophrenics and normal controls: effects of recording site and stimulation interval on the P50 wave. Schizophrenia Research, 4, 31-40.

Oades, R. D. (1995). Connections between studies of the neurobiology of attention, psychotic processes and eventrelated potentials. Electroencephalography and Clinical Neurophysiology, Suppl. 44, 428-438.

Oades, R. D., Bunk, D. \& Eggers. C. (1992). Paranoid schizophrenics may not use irrelevant signals: the use of measures of blocking and of urindry dopamine. Acta Paedopsychiatrica, 55, 183-184.

Oades, R. D., Röpcke, B. \& Eggers, C. (1994). Monoamine activity reflected in urine of young patients with obsessive-compulsive disorder, psychosis with and without reality distortion and healthy subjects: an explorative analysis. Journal of Neural Transmission. (GenSect), 96. 143-159.

Oades, R. D. Zerbin, D. \& Eggers, C. (1993). Stimulus-Vergleichsprozesse bei psychotischen Jugendlichen mit paranoiden und nicht paranoiden Symptomen: "Mismatch negativity" deutet auf differenzierte Beeinträchtigungen hin. In Baumann, P. (Ed.), Biologische Psychiatrie der Gegenwart (pp. 69-73). Wien: Springer-Verlag.

Perlstein, W. M., Fiorito, E., Simons, F. \& Graham, F. K. (1993). Lead stimulation effects on reflex blink, exogenous brain potentials, and loudness judgement. Psychophysiology, 30, 347-358.

Pfefferbaum, A., Wenegrat, B. G., Ford, J. M., Roth. W. T. \& Kopell, B. S. (1984). Clinical application of the P3 component of event-related potentials. If. dementia, depression and schizophrenia. Electroencephalography and Clinical Neurophysiology, 59, 104-124.

Pigott, T. A., Pato, M. T., Bernstein, S. E., Grover, G. N., Hill, J. L., Tolliver, T. J. \& Murphy, D. L. (1990). Controlled comparisons of clomipramine and fluoxetine in the treatment of obsessive-compulsive disorder. Archives of General Psychiarry, 47, 926-932.

Polich. J. (1990). P300, probability and interstimulus interval. Psychophysiology. 27, $396-403$

Posner, M. I. \& Dehaene, S. (1994). Attentional networks. Trends in Neuroscience, 17, 75-79. 
Pribram, K. H. \& McGuinness, D. (1993). Anention and para-attentional processing: event-related potentials as tests of a model. Annals of the New York Academy of Science, 658, 65-92.

Rapoport, J. L. (1991). Recent advances in obsessive-compulsive disorder. Neuropsychopharmacology, 5, 1-10.

Roth, W. T., Horvath, T. B., Pfefferbaum, A. \& Kopell, B. S. (1980). Event-related potentials in schizophrenics. Electroencephalography and Clinical Neurophysiology, 48, 127-139.

Reed, G. F. (1991). The cognitive characteristics of obsessional disorder. In Magaro, P. A. (Ed.). Cognitive Bases of Mental Disorder (Vol. 1, pp. 77-99). Newbury Park CA: Sage.

Scarone, S., Colombo, C., Livian, S., Abbruzzese, M., Ronchi, P., Locatelli, M., Scotti, G. \& Smeraldi, E. (1992). Increased caudate nucleus size in obsessive-compulsive disorder: detection with magnetic resonance imaging. Psychiatry Research (Neuroimaging), 45, 115-121.

Schupp, H. T., Lutzenberger, W., Rau, H. \& Birbaumer, N. (1994). Positive shifts of event-related potentiats: a state of contical disfacilitation as reflected by the startle reflex probe. Electroencephalography and Cinical Neurophysiology, 90, 135-144.

Schwartz-Place, E. J. \& Gilmore, G. C. (1980). Perceptual organization in schizophrenia. Joumal of Abnormal Psychology, 89, 409-418.

Schwarzkopf, S. B., Lanberti, J. S., \& Smith, D. A. (1993). Concurrent assessment of acoustic startle and auditory P50 evoked potential measures of sensory inhibition. Biological Psychiatry, 33, 815-828.

Shelley, A. M., Ward, P. B., Catts, S. V., Michie, P. T., Andrews, S. \& McConaghy. N. (1991). Mismatch negativity: an index of a preattentive processing deficit in schizophrenia. Biological Psychiatry, 20, 1059-1062.

Siegel, C., Waldo, M., Mizner, G., Adler, L. E. \& Freedman, R. (1984). Deficits in sensory gating in schizophrenic patients and their relatives: Evidence obtained with auditory evoked responses. Archives of General Psychiatry, 41, 607-612.

Straube, E. R. \& Oades, R. D. (1992). Schizophrenia: empirical research and findings. New York: Academic Press.

Swedo, S. E., Schapiro, M. B., Grady, C. L., Cheslow, D. L., Leonard, H. L., Kumar, A., Friedland, R., Rapoport. S. 1. \& Rapoport, J. L. (1989). Cerebral glucose metabolism in child-onset obsessive-compulsive disorder. Archives of General Psychiatry, 46, 518-523.

Swerdlow, N. R.\& Geyer, M. A. (1993). Prepulse inhibition of acoustic startle in rats after lesions of the pedunculopontine tegmental nucleus. Behavioral Neuroscience, 107, 104-117.

Swerdlow, N. R., Braff, D. L. \& Geyer, M. A. (1990). GABAergic projection from nucleus accumbens to ventral pallidum mediates dopamine-induced sensorimotor gating deficits of acoustic startle in rats. Brain Research, 532, 146-150.

Swerdlow, N. R., Caine. S. B. \& Geyer, M. A. (1991). Opiate-dopamine interactions in the neural substrates of acoustic startle gating in the rat. Progress in Neuro-Psychopharmacology and Biological Psychiatry, 15, 415-426.

Swerdlow, N. R., Benbow, C. H., Zisook, S., Geyer, M. A. \& Braff, D. L. (1993). A preliminary assessment of sensorimotor gating in patients with obsessive compulsive disorder. Biological Psychiatry, 33, 298-301.

Treisman, A. M. (1960). Strategies and models of selective attention. Psychological Review, 76, 282-299.

Velasco, F. \& Velasco, N. (1979). A reticulo-thalamic system mediating proprioceptive attention and tremor in man. Neurosurgery, 4, 30-36.

Waldo. M. C., Adler, L. E. \& Freedman, R. (1988). Defects in auditory sensory gating and their apparent compensation in relatives of schizophrenics. Schizophrenia Research, 1, 19-24.

Waldo, M. C., Gerhardt, G., Baker, N., Drebing. C., Adler, L. E. \& Freedman, R. (1992). Auditory sensory gating and catecholamine metabolism in schizophrenic and normal subjects. Psychiatry Research, 44, $21-32$.

Wu, M.-F., Jenden, D. J., Fairchild, M. D. \& Siegel, J. M. (1993). Cholinergic mechanisms in startle and prepulse inhibition: effect of the false precursor N-aminodeanol. Behavioral Neuroscience, 107, 306-316. 